\title{
IMPACT OF ETHICS ON HUMAN RESOURCE AND THE PROCESS OF MANAGERIAL DECISION MAKING
}

\author{
${ }^{1}$ Ms. Ambika Venkatesh ${ }^{2}$ Ms. Dippi Verma
}

\begin{abstract}
The current paper offers a theoretical framework of ethical behavior and a comparative analysis of ethical perceptions of male managers and female managers of small and medium size firm. The primary research provides basic data on the standards of ethics in men and women and the factors that are making the manager or decision maker to fall from the set ethical standards. Business owners often face difficult ethical dilemmas, such as whether to cut corners on quality to meet a deadline or whether to lay off workers to enhance profits. $A$ current ethical debate concerns the gender issue. That is the involvement of the powers resting with a male or a female would be a better criteria in an organizational setup. The intense pressures of business may not always allow the luxury of much time for reflection, and the high stakes may tempt to compromise our ideals. How should we respond? No doubt, we already have a well-developed ethical outlook. Nevertheless, by considering various approaches to ethical decision making, we may be better able to make the right choice when the need arises.
\end{abstract}

The subject of business ethics is definitely complex. Fair-minded people sometimes have significant differences of opinion regarding what constitutes ethical behavior and how ethical decisions should be made. This article discusses approaches in business that can be used to oonsider ethical questions. The method we prefer may not suit everyone. Hopefully, by considering the alteriatives, we will be able to make decisions that are right for

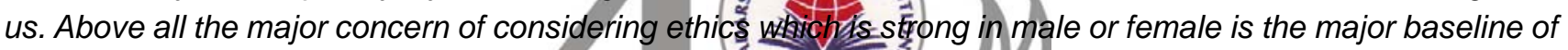
the study and a sincere attempt to understand the reasons for the same is made.

Key Words: Ethics, Male, Female, Decision Making.

\section{Introduction}

What is Ethics? Simply stated, ethics refers to standard of behavior that tells us how human beings ought to act in the many situations in which they find themselves-as friends, parents, children, citizens, businesspeople, teachers, professionals, and so on.

It is definitely required to identify what ethics is NOT:

- $\quad$. The same as feelings. Feelings provide important information for our ethical choices. Some people have highly developed habits that make them feel bad when they do something wrong, but many people feel good even though they are doing something wrong. And often our feelings will tell us it is uncomfortable to do the right thing if it is hard.

- ..Religion. Many people are not religious, but ethics applies to everyone. Most religions advocate high ethical standards but sometimes do not address all the types of problems we face.

- ..Following of the law. A good system of law does incorporate many ethical standards, but law can deviate from what is ethical. Law can become ethically corrupt, as some totalitarian regimes have made it. Law can be a function of power alone and designed to serve the interests of narrow groups. Law

1 Ms. Ambika Venkatesh, MBA Department, Administrative Management College, Bangalore Tel : 09945215585 E-mail : reachambika@gmail.com

2 Ms. Dippi Verma, MBA Department, Administrative Management College, Bangalore Tel : 09448328635 E-mail : dippiverma @gmail.com 
may have a difficult time designing or enforcing standards in some important areas, and may be slow to address new problems.

- ..Following culturally accepted norms. Some cultures are quite ethical, but others become corrupt or blind to certain ethical concerns. "When in Rome, do as the Romans do" is not a satisfactory ethical standard.

- ..Science. Social and natural science can provide important data to help us make better ethical choices. But science alone does not tell us what we ought to do. Science may provide an explanation for what humans are like. But ethics provides reasons for how humans ought to act. And just because something is scientifically or technologically possible, it may not be ethical to do it.

Why then is Identifying Ethical Standards so Hard

There are two fundamental problems in identifying the ethical standards we are to follow:

1. On what do we base our ethical standards?

2. How do those standards get applied to specific situations we face?

If our ethics are not based on feelings, religion, law, accepted social practice, or science, then what are they based on? Many philosophers and ethicists have worked on these philosophies and given remedial solutions that can be used situationally. But it is very important for us to understand individually as to what is that we are intending to follow in our lives and to what extent we have the courage and vigor to stand by and adhere to our decisions.

Then What is ethical Decision making all about? And how far is it important from the managerial or business point of view. Consider this - is it ethical that CEO's get paid salaries hundreds of times greater than their most junior employees? You could argue a CEO contributes more to the overall wealth and health of the company and should be appropriately rewarded, however, others may say it is an unfair, indefensible abuse of power.

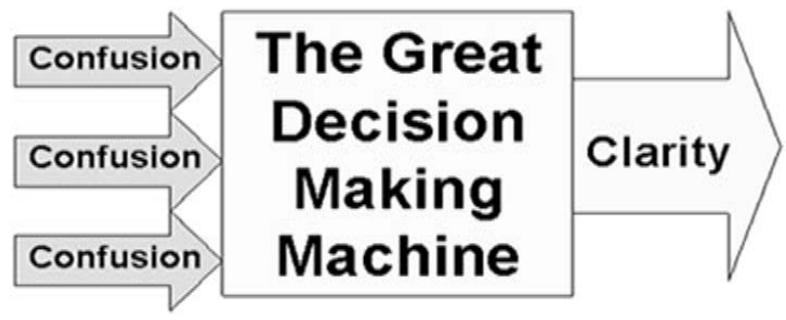

So when you've got a tough decision to make,. What are your options? Which is the best answer?

Holding out for the perfect answer wastes time. Your time, and unmade decisions are just stressful.

Our findings in the paper reveal the extent to which the message of business integrity is gaining or losing grounds and its importance in men and women. It does this by means of respondent's 'judgments of acceptable responses to 13 scenarios profiling common mbusiness situations with questionable ${ }^{\mathrm{O}}$ etthicak dimensions. Respondents were surveyed by Amai Eand structured interview in Bangalore. They Weréch also asked questions about themselves and their businesses, as well as the ethical climate within their companies. Based on responses from over 150 male and female managers and employees at different levels (from firms of small and medium sizes in India, primarily Bangalore) to our scenarios during month of December 2010 and January 2011, we found evidence of trends in expected ethical behavior.

\section{Comparing Decision Making Models}

How do I make a decision? Comparing decision making models, you can see there are many ways to reach a conclusion. The decision making models have been grouped into 3 types;

\section{The Rationale Approach}

This can be effective when time allows for the considered deductive reasoning, but it can lead to "analysis paralysis". Sometimes it is best to ignore your head and trust your gut. A Rationale Decision Making model usually includes the following steps: 
- Identify the problem or opportunity

- Gather and organize information

- Analyze the situation

- Develop several options

- Evaluate and assign a value to each option

- Select the option which emerges as the best

- Act decisively on that option

The pros - being able to set emotion aside, and approach a decision with structure and discipline. The con - that humans are not always rational, and the 'best option' may not always be the 'right' one when you factor in other people associated with the decision or ethical issues.

\section{The Intuitive approach}

For example, most people would safely use intuitive decision making when choosing a restaurant for a special occasion or choosing a holiday book to read. Intuitive reasoning is not the full story, especially in "do or die" situations where there is no time to "process" your decision making criteria, or when you've got a gut bug. An intuitive decision making model is much less structured and favors subjective rather than objective judgement. It depends on inputs like:

- Pattern recognition - Events \& information pattern and using them to configure a course of action.

- Similarity Recognition - Similarities in past and present as recognized cause $\mathrm{N}$ effect in a given situation.

- Salience - understanding the importance of information and the way it affects personal judgment.

Pro-Decisions can be made quickly but decision maker leans on personal experience\& judgment.

Con-Emotion, bad or too little experience may cloud judgment and cause a poor or 'impulse' decision making.
Gary Klein recognition primed decision making model-A combination of intuitive and rational reasoning.

Here decision maker assesses the situation quickly, compares it to past situations, recognizes patterns and creates a mental 'action script' that runs through the scenario to conclusion. This model is practically demonstrated every day by people involved in "life or death"; scenarios such as airline pilots, emergency response teams or war veterans. When the decision maker is experienced, the recognition patterns are more developed, giving them more past scenarios to extrapolate data from and making it more likely that their first option is the best one. For younger or less experienced decision makers, the rational working through of mental scenarios and troubleshooting of possible problems takes a more prominent role.

Pros-Lie in the fact that both intuitive \& rational reasôning used, and experience can factor in. This hás coined the term "pre-mortem"; when you gaze Ainto=an imaginary crystal ball and predict what happens if you follow a particular course or script. Waskat worked? What failed? This mental simulation allows you to "learn"; before the event and prevent problems before they arise.

Con may be that some people may use this model when one of the other two would be more appropriate for example for a novice or for a non critical decision.

\section{Ethical Issues helping in Effective Decision making}

Ethical decision making affects more than our working life. Its a tricky business, but we can make it more palatable, workable decisions if we follow these 5 simple steps.

\section{Think! Is it an ethical issue?}

Being ethical does not always mean following the law. And just because something is possible doesn't mean it is ethical, hence there is a global debate on bio-technology advances as cloning. And ethics and religion do not always concur. Listen to your instincts - if it feels uncomfortable making the decision on 
your own, get others involved and use their collective knowledge and experience to make a more considered decision.

\section{Get the facts}

It is very important to gather facts from different sources before we self rely and proceed with our own beliefs. Reconsider on What you know and what you don't know? Who are the people affected by your decision? Have they been consulted? What are your options? Have you reviewed your options with someone you respect and adhere on?

\section{Evaluate alternative actions}

There are different ethical approaches which may help you make the most ethical decision.

* Utilitarian Approach - which action results in the most good and least harm?

* Rights Based Approach - which action respects the rights of everyone involved?

* Fairness or Justice Approach- which action treats people fairly?

* Common Good Approach - which action contributes most to quality of life of affected people?

* Virtue Approach - which action embodies the 97 character strengths that you value?

\section{Test your decision}

Take time rather than a faulty or a hurried wrong decision. Evaluate- Could you comfortably explain your decision to your mother? To the man in the street? On television? If not, you may have to rethink your decision before you take any action.

\section{Just Do It - but what did you learn?}

Once you've made the decision, then don't waste time in implementing it. Set a date to review your decision and make adjustments if necessary. Often decisions are made with the best information to hand at that time, but things do change, and your decision making needs have to be flexible enough to change too.

\section{Review of Literature}

Several studies suggest the need for separating research with Gender issues in organizations on human resource at key managerial decision making process interms of ethical attitudes. In an article by Longenecker and Schoen (1975) entrepreneurial managers were found to have several different approaches to business in such areas as innovation, risk-taking, and independent action than their counterparts in larger organizations. A study by Erika Wilson (1980) compared perceptions and attitudes of owners or managers of small businesses with employees of larger organizations on Gender and social responsibility. Chrisman and Fry (1982) also examined social responsibility using comparisons between small and large organizations with Gender. The study indicated more apparent understanding by smaller businesses of social responsibility issues than larger businesses. "Small businesses seem to be in touch with the expectations of society, for the up omost part, and, in fact, to be more critical of their Aperformance than is the general public" (Chrisman (2) important internal and external factors that affect galomall business ethics differently from large businesses. Internal factors included such things as different norms and pressures from community and Opeerslals well as the differences in fear of punishment. Differences in external factors included the impact of trade organizations, churches, and competition. Longenecker, McKinney, and Moore (1989) compared small and large business managers' views of ethics. Several significant differences between the views of small and large business managers on ethical issues were noted. This study is of particular relevance to the research reported here because these authors also used scenarios and an ethics rating scale. The Longenecker, McKinney, and Moore scale was a seven-point univariate measure anchored by "never acceptable" to "always acceptable." In their results they noted that ". . . the uniqueness of small business extends to ethical issues" (Longenecker, McKinney and Moore 1982, 31). One final justification for separating ethical studies of smaller and larger businesses comes from the book Moral Mazes by the sociologist Robert 
Jackall (1988). In it he describes the sociology of bureaucratic organizations in the U.S. from the view of managers in those organizations. As Jackall portrays it, ethical decisions are heavily dependent on the complex interplay of the individual values of top level management and have little to do with personal values. The small business owner/manager does not have the same constraints or guidance and can employ personal values to a much greater degree. In a study by Payne and Duhon, the authors note that.. "the ethical challenges of small business entrepreneurs have not received much specific attention" (Payne and Duhon 1990, 29). And further, that "much deeper analysis and understanding ... is needed by researchers ... and entrepreneurs themselves" (Payne and Duhon 1990, 32). G.L. Shostack echoes this sentiment in the statement, "Entrepreneurs who value their companies and who hope to see them prosper must take a firm stand on ethics" (Shostack 1990, 50). This research helps improve understanding of small business ethical perceptions.

All these studies concentrated on the differences and criticalities of Large and Small business Organisations with ethical consideration and the relevance along with impact of the same with gender imvolvement in business process.

\section{Rationale of Study}

We tested research questions by creating an Ethics Index. This study was undertaken primarily to understand the impact and existence of ethics in todays decision making processes in organizations and their genuinity and reliability if we consider the gender factor. Also an attempt is made to understand the reasons and situations that make these individuals involve into unethical practices

RQ1: Is there a difference in ethical standard between male and female employees of small and medium firms with reference to Karnataka.

\section{Objectives}

- To study the implementation of Ethics in Decision Making being gender specific.

- To study the practices of Ethics in the competitive work life and with gender differences.
- To study the factors affecting Ethical Decision making.

- To study to what extent unethical practices have become a routine in our day to day lives.

\section{Methodology for Baseline Studies}

The research questions explored in this study are presented first followed by a discussion of the multidimensional ethics scale and other measures, a characterization of the respondent groups, and finally, a presentation of the scenarios are used as the response stimuli. The research questions are laid with a purpose of furthering our understanding of how and why both male and females react to ethical issues. A manipulation check of the ethical content using the univariate measure of ethics revealed important differences and the comparison of ethical perceptions of the genders concerning scenario/ situational analysis.

\section{Source of Primary Data}

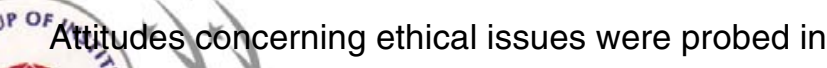
Athe whole of Karnataka through surveys of mangers and professionals in both large and small fikn's. The database used for analysis of ourtwo research questions was based on surveys conducted in Dec 2010, and January 2011. A questionnaire was given to 300 business 1971 toprofessionals as well as academicians .Out of 300 , 176 questionnaires were given to males and 124 to females of different levels. Actually responses have been collected from 78 males and 72 females of different hierarchical capacities. The responses were both by means of mail responses to the questionnaire and One-to-One talks with these employees probing the given 13 scenarios accordingly.

\section{Measurement of Ethics}

The three-page questionnaire developed for our ethics research contained thirteen vignettes, each involving a business decision having ethical overtones (please refer Appendix 1 for a list of the vignettes used in the survey). Respondents were asked to indicate the degree to which they found each action compatible with their own ethical views. They recorded their opinions by circling a seven point scale ranging from 1 (Never Acceptable) to 7 
(Always Acceptable). The midpoint on the scale i.e.. 4 was labeled "Sometimes Acceptable"; Point 2 was labeled as 'Rarely Accepted', point 3 was labeled as 'Occasionally Accepted', and Point 5 was labeled as 'Frequently Accepted' and 6 as 'Persistently Accepted' situations. The vignettes dealt with a wide variety of business situations and were designed to address ethical issues in different functional areas of business. Some are clearly illegal, whether recognized as such by respondents or not, while others involve questionable or debatable ethical characteristics.

The use of scenarios or vignettes, according to Fritzsche and Becker (1982), permits one to inject more background information and detail into an ethically questionable issue. A questionnaire incorporating vignettes into its design, therefore, is thought to elicit a higher quality of data in this type of research than is possible from simple questions. The potential for systematic bias was minimized by having knowledgeable individuals assess the content or face validity of the vignettes prior to their inclusion in the questionnaire. An overall Ethics Index was computed for each individual by summing their responses to the thirteen vignettes and computing an arithmetic mean. Additional questions classified respondents according to age, size of firm, employment level, and other customary survey classification variables. Then, all responses were accumulated, edited, and entered into a database.

\section{Analysis and Results}

\section{Reponses to Surveys}

\begin{tabular}{|c|c|c|c|}
\hline Gender & No. of questionnaire given & 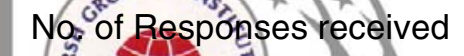 & Response Rate \\
\hline Male & 176 & & $44.31 \%$ \\
\hline Female & 124 & & $58.06 \%$ \\
\hline Total & 300 & $\begin{array}{l}150 \text { CARS } \\
1071+02011\end{array}$ & $50 \%$ \\
\hline
\end{tabular}

As can be seen in Table 1, the response rates survey is around $50 \%$.Only $44.31 \%$ of males and $58.01 \%$ females have given their responses taking overall response rate to $50 \%$.We recognize the ever present possibility of non-response bias in databases when response rates are not near 100 percent. A higher response rate would certainly have been desirable, we were encouraged that respondents came wide range of management levels, professions, ages, and business sizes.

A brief profile on samples based on age group, gender, Industry, employee status, size of the firm is shown in Table 2.

\section{Sample profile - Gender}

Table 2

\begin{tabular}{lcc}
\hline Gender & No. of respondents & \%age response \\
\hline Male & 78 & 52 \\
Female & 72 & 48 \\
Total & 150 & 100 \\
\hline
\end{tabular}

$52 \%$ of total respondents are males and $48 \%$ respondents are female. 


\section{Age Group}

\begin{tabular}{lll}
\hline Age Group & Male(\%) & Female(\%) \\
\hline Between 25yrs and 30yrs & 8.23 & 3.67 \\
Between 30yrs and 40yrs & 43.62 & 57.26 \\
Between 40yrs and 50yrs & 36.25 & 28.21 \\
More than 50 yrs & 11.9 & 10.26 \\
\hline
\end{tabular}

Major parts of responses have been collected from age group between 30yrs and 50yrs.

\section{Employee Status}

\begin{tabular}{lll}
\hline Employee Status & Male(\%) & Female(\%) \\
\hline & & \\
Low Level management & 18 & 33 \\
Medium Level Management & 41 & 36 \\
High level management & 10 & 05 \\
Non Management & 18 & 21 \\
Others & 13 & $* *$ \\
\hline
\end{tabular}

Male respondents were manly from medium level of mìnanamement. Female respondents are either from medium level of management or low level of management. othess compitises of entrepreneurs and business persons.

Size of the firm

Size of the firm percentage

Less than 100 employee 2271 to 2011

More than 100 employee 73

Data have been collected mostly from medium size and small size firms.

Respondents were asked one question regarding change in ethical standards in last two years.

\section{Change in ethical standards}

\begin{tabular}{ll}
\hline Ethical Standard & $\%$ response \\
\hline Improved & $17 \%$ \\
Declined & $61 \%$ \\
No Change & $22 \%$ \\
\hline
\end{tabular}

Most of the respondents believed that ethical standards have come down and it has become as a routine activity of our lives. Some unethical practices are so infused in our life that it has become a normal activity of our lives. And it has become so obvious that we are rarely able to distinguish between the Right and the Wrong. 


\section{Factors influencing deviation in Ethical Standards}

Factors that influence ethical perceptions and behavior are multidimensional; that is, they are rooted in differences between individuals, variations in their organizational settings, and the interplay between the two. Respondents were asked to identify the factors and arrange them in order of preference which influences them to change their ethical standards. The factors were identified as Personal, Situational, Organizational and Societal at the forefront. $33 \%$ respondents said organizational pressure is making them change their ethical standards, $21 \%$ respondents attributed it to personal factors , $23 \%$ respondents said that situation factor is making them change their ethical standards and $16 \%$ believed societal factor is the main influencing factor. $7 \%$ respondents avoided this question by choosing the option "Not Sure". But most of the respondents believed that change in ethical standards is not an outcome of one factor. It is two or more factors which influence an individual to change their ethical standards.

\begin{tabular}{ll}
\hline Factor & \% response \\
\hline Organisational & 33 \\
Situational & 23 \\
Societal & 16 \\
Personal & 21 \\
Not sure & 07 \\
\hline
\end{tabular}

\section{Analytical Techniques :}

Statistical tool was used to analyze the data and to generdteffreguencies and other descriptive Statistics. Ethical index of male and female was calculated using the Mean Eormula differences between the two means.

Evaluation of Research Question :

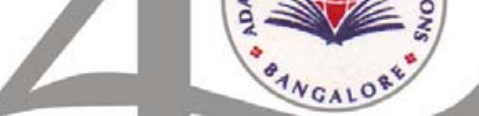

As already discussed the issue of overall change in the attitudes of business regarding ethics, we proposed the following research question:

RQ1: Is there a difference in ethical standard between male and female employees of small and medium firms with reference to Karnataka.

Table 3 displays data representing the Ethics Index for all respondents, regardless of firm size.

\section{Ethics Index for Respondents}

Table 3:

\begin{tabular}{lll}
\hline Particulars & Mean Score & No.of respondents \\
\hline Male & 3.49 & 78 \\
\hline Female & 3.06 & 72 \\
\hline
\end{tabular}

The mean is computed as the summed average of responses to 13 vignettes (Appendix) $\mathrm{t}$-test $=.06$ (t-test is a test of difference of two means)

Pressure to engage in Unethical practice :

Level of pressure percentage responding

\begin{tabular}{lr}
\hline High & $10 \%$ \\
Medium & $57 \%$ \\
Low & $09 \%$ \\
No Pressure & $24 \%$ \\
\hline
\end{tabular}


Our finding indicates that face medium pressure to get engaged in unethical practice. It is noticed that managers or professionals of medium level management mostly get pressure to get engaged in unethical practice. The study says that this pressure is generally high on a male professional rather than females.

\section{Discussions, Implications, Study, Limitations and scope for future research}

As with any research, our study has its limitations. For example, we know that the standards of ethical behavior can vary across various contexts-e.g., country setting, regional venue, industry sector, and historical era-but some of these are not represented in our database. Data has been collected from Karnataka state only. So our conclusion may not generalize to national settings. Very few people from higher management could be approached. So results are based on responses of medium and lower level management professionals. Further complicating this stream of research, clear ethical standards are difficult to discern in some cases. Specifically, older individuals tended to be more ethical than younger respondents, women were more likely to reject unethical behavior than men, and highly educated professionals were significantly more intolerant of conflict of interest issues. Other personal factors such as marital status, annual household income, and organizational rank had no significant linkage with ethical behavior. Though we did not see evidence to suggest these variables had substantive impact in our study, we also did not test or control for their influence.

On the research question to study the difference between male and female ethical standards, the study shows that there is a big difference in the ethical standards of male and female. The value calculated for difference of two means (t-test) is 0.06 which indicates that there is a wide range of difference between ethical standards of male and females. The female respondents show increasingly positive selections in their responses to the 13 vignettes (Appendix), as reflected in an Ethics Index. This result strongly supports the contention of gender socialization theory that men and women bring different ethical standards and values to the work environment.
The value of a multivariate measure, when applied to situations such as reported in this study, is that results can lead to further hypotheses about specific actions and behaviors. The single univariate measure indicates similarities and differences in the ethical perceptions of the two groups, but no information concerning the ideas of fairness or relativism or implied contract would be available without the multivariate measure. Much is to be done to help our understanding of unethical behavior with gender specifications. This study represents one more step on the long road toward that objective.

Finally, the focus of our study is on differences between male and female ethical standards. As discussed females were more likely to reject unethical behavior than men. But when it comes on protesting for unethical practice ,they prefer to remain quiet and become a part of practice under compulsion. The study showed that women are not ready to indulge in unethical practice openly. Women also are more concerned about openness and fairness, she says, because that's what they've been taught. By contrast, "little boys are taught that up ofyinning is every-thing. If they are playing a game and [the ballis] a little bit out, well, you can call it in." AGiven the widespread perception that the ethical standards of the business community are declining, the $\%$ greater infusion of women at management levels takes on added significance. Yet it would be simplistic to say that women's influence will lead to higher ethical levels. If women are compassionate and men are fair, who is more ethical? If women managers reach ethical decisions with greater concern for relationships and feelings and less concern for rights and rules, it is a matter of individual opinion whether that raises ethical standards. What seems more certain is that women's increasing influence in organizations will bring about differences in how ethical problems are perceived and resolved. women are quicker at picking up on deception than men. Because of their ability to recognize unethical behavior, some researchers feel that women are in a better position to deal with it. Finally we can say people from both genders who are either ethical or unethical. Women are more relationship oriented than men. So to categorize that women have higher ethical standard is not correct. We find deviation $s$ in women ethical standards also if they are in shoe of men. Despite limitation this study is showing that female have higher ethical standard. Further research is required on factors determines females ethical standard and factor which can bring change in it. 


\section{Conclusion}

The study revealed that women used a higher level, principle-based reasoning than men. The study says that in the given sample females have higher ethical standard. We have calculated an ethical index of respondents. Over all it is neither high nor low. But linkage between perception and actual behavior in market place is likely to be deviated by the presence of pressure to act unethically. This pressure may derive from a corporate culture that pushes for profits over principle, a customer who demands some form of unethical "favor" in exchange for his or her business, intense and disproportionate regulatory monitoring, and other factors. To capture this effect, we asked respondents the following question: "How much pressure do you feel personally within your organization to engage in what you perceive to be unethical behavior?"

The primary reasons here being the culture, the broughtup, traditions, practices, and above all a boy is always taught the spirit of "winning" while a girl right from her childhood is taught to analyse the correct and the incorrect, standby, be right always, blamed, feared and the like. In this kind of an upbringing she is not more proned towards success but more inclined towards doing the right way as she knows that she is answerable, her commitments, responsibilities, the shamefulness if blamed and all such factors. While a boy is brought up in such a way that he realizes very soon that am the head of the family and all are dependent on me. Hence either of the ways I am the only person to take care of the wants and requirements of the family. Hence at most of the times he has to forgo the concept of Ethics when it is all about the happiness, cheer and peace of his family.

Thus inshort we cannot blame either one of them from following/not-following ethics in their personal and professional lives as there are reasons for the same. But yes we can definitely limit our requirements and educate our people/family of our limitations and develop the seeds of ethics so that we are not proned to or mesmerized or forced to follow these unethical ways. Its definitely true that If it can be Once, then it can be many times Too. So lets chalk out to say NO at the very first time. It might be difficult but Never Impossible. When the Tough gets going, the going gets tougher.

\section{Bibliography}

- Fritzsche, D. J. and Becker, H. (1982). "Business Ethics of Future Marketing Managers,"

- Journal of Marketing Education Glover, S. H., Bumpus, J. E., Logan, J. E., and Ciesla, J. R. (1997).

- "Re-Examing Influence of Individual Values on Ethical Decision Making," Journal of Business Ethics,

- Brenner, S., and Molander, E. (1977). "Is the Ethics of Business Changing?" Harvard Business Review,

- Deaux K. "Sex Differences" M.R. Roseenzweig and L. W. Porter (eds.) Annual Review

- of Psychology

- Gray, John, Men are from Mars Women are from Venus. New York

- www.google.com

*

www.scribd.com

www.indianmba.com
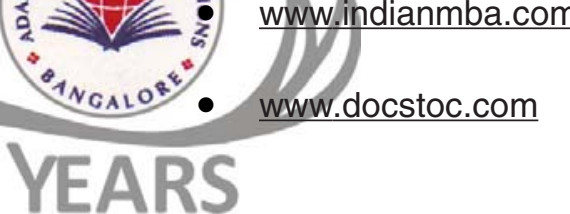


\section{APPENDIX}

Instances \& your fair views over the situational analysis:

You have to record your opinions by circling a seven-point scale ranging from 1 (never acceptable) to 7 (always acceptable).

1- not accepted,

2- rarely accepted,

3- occasionally accepted,

4- sometimes accepted,

5- frequently accepted,

6- persistently accepted,

7- always accepted

Considering you in this situation, according to you, it is -

1) To increase the profit a general manager used a production process which exceeded legal limits for environmental pollution.
a)1 b)2
c)3
d) 4
e) 5
f) 6
g)7

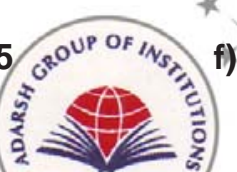

2) Because of pressure from his brokerage firma a stock broker recommended a type of bond which he did not consider as a good investment.
a)1 b)2
c)3
d)4
YEêt5
f)6
g)7
1971 to 2011

2) A small business received one fourth of its gross revenue in the form of cash. The owner reported only one half of cash receipts for income tax purpose.
a)1 b)2
c)3
d) 4
e)5
f)6
g)7

4) A company paid an amount of $\$ 350000$ as consulting fees to an official of a foreign country. In return the official promised his assistance in obtaining a contract which would produce $\$ 10$ million profit for the contracting company.
a)1 b)2
c)3
d) 4
e)5
f) 6
g)7

5) A company president found that the competitor had made an important scientific discovery which would sharply reduce profit of his own company. He then hired a key employee of the competitor in an attempt to learn the details of the discovery.
a)1 b)2
c)3
d) 4
e) 5
f) 6
g) 7 
6) A Highway building contractor deployed the chaotic bidding situation and cut throat competition. He therefore reached an understanding with other major contractor to permit bidding which would provide a reasonable profit.
a)1 b)2
c)3
d)4
e) 5 f) 6
g)7

7) An engineer discovered what he perceived to be a product design flaw constituted a safety hazard. His company declined to correct the flaw. The engineer decided to keep quite rather than taking his complaint outside the company.
a) 1
b)2 c)3
d)4
e)5
f) 6
g)7

8) An employee received an application for a supervisors' position from two equally qualified applicants but hired male applicant because he thought some employees might resent being supervised by a female.
a)1 b)2
c)3
d)4
e)5
f)6
g)7

9) As a part of a marketing strategy for a product the producer changed its color and marketed it as a new and improved product even though its other characteristics were unchanged.
a)1 b)2
c)3
d) 4
e) $5 \quad *$ f) 6
g) 7

10) An owner of a small firm obtained a free co्रp xa business friend rather than spending Rs. 5000 to obtain his own program.
a) 1
b)2
c)3
d) 4
e) 5
f) 6
g)7

11) A corporate director learned that his companylintended/to announce a stock split and increase its dividend. On the basis of this information, he bought additional shares and sold them at again following the announcement.
a) 1 b)2
c)3
d)4
e) 5
f) 6
g)7

12) A corporate executive promoted a loyal friend and competent manager to the position of divisional vice president in preference to a better qualified manager with whom he had no close ties.
a)1 b)2
c) 3
d)4
e) 5
f)6
g) 7

13) A private educational institute to attract more admissions made many promises, most of which were not fulfilled after the admission due to decline in number of admissions and revenue.
a)1 b)2
c)3
d) 4
e)5
f) 6
g)7 